\title{
O aluno como co-construtor e desenvolvedor de jogos educacionais
}

\author{
Liane Margarida Rockenbach Tarouco* \\ Mary Lucia Pedroso Konrath ** \\ Anita Raquel da Silva Grando *** \\ Centro Interdisciplinar de Novas Tecnologias na Educação \\ Universidade Federal do Rio Grande do Sul \\ Brasil
}

\begin{abstract}
Resumo
O presente artigo tem como objetivo discutir a importância dos jogos como propiciadores de aprendizagem. Através do uso de modelos pré-definidos, onde se podem inserir informações e imagens, o estudante se define como co-construtor dos seus próprios jogos, de acordo com seu interesse ou com o assunto que está sendo estudado. Além disso, serão apresentadas algumas experiências de estudantes do Curso de Pedagogia e professores do Programa de Pós-graduação em Informática na Educação, ambos da Universidade Federal do Rio Grande do Sul, quando solicitados a desenvolver jogos educativos simples, criativos e de caráter pedagógico, utilizando ferramentas de autoria, tais como Hot Potatoes e Macromedia Flash MX.
\end{abstract}

Palavras-chave: jogos educacionais, Andragogia, construção, Macromedia Flash MX, Hot Potatoes

\section{Introdução}

Vive-se hoje no período pós-industrial, do qual emerge uma nova sociedade, cujo principal fator de produção e de transformação é o conhecimento. Nessa sociedade, as informações multiplicam-se e distribuem-se rapidamente, tornando-se indispensável à busca e a seleção daquelas que podem ser relevantes para auxiliar nas respostas aos questionamentos e, conseqüentemente, contribuir para a construção de conhecimento. Exigem-se, assim, indivíduos com uma postura crítica e criativa diante da realidade.

Esta era é também a era do aprendizado permanente, que não se restringe apenas a um período de vida do indivíduo, mas é contínuo ao longo desta. E é em meio a tal realidade que se percebe a importância de se pensar em estratégias de ensino para adultos que buscam qualificação dentro de suas profissões, sem a repetição dos modelos que vêem o aprendiz como "passivo" no processo de ensino-aprendizagem.

\footnotetext{
Doutora em Engenharia Elétrica pela USP, Mestre em Ciência da Computação pela UFRGS.

** Mestranda em Educação e Especialista em Informática na Educação pela UFRGS.

pedagoga e aluna do curso de especialização Informática na Educação pela UFRGS 
Esse artigo pretende discutir a importância dos jogos como propiciadores de aprendizagem e mostrar experiências de co-construção de jogos educativos través de modelos pré-definidos e de desenvolvimento de jogos simples, criativos e de caráter pedagógico, utilizando ferramentas de autoria, tais como Hot Potatoes e Macromedia Flash MX.

Neste cenário, a educação de adultos ganha um novo status e uma ciência que trata especificamente deste tema desponta: a Andragogia.

\section{Andragogia}

Através da observação de crianças e adultos, pode-se perceber diferentes formas de interpretar o mundo, relacionar-se com outros indivíduos, solucionar problemas e aprender coisas novas. O ser humano em crescimento passa por fases de dependência extrema durante a infância, até torna-se um ser independente em ações e decisões quando adulto. (CAVALCANTI, 1999). Levando em consideração os aspectos mencionados, vários pesquisadores observaram que existe diferença entre a educação de crianças e adultos.

Knowles (CAVALCANTI, 1999), percebendo as diferenças no aprendizado de adultos e crianças, introduziu e definiu o termo Andragogia. Segundo ele, o termo refere-se à arte e a ciência de orientar adultos a aprender. Se o adulto atinge um grau de independência em que é capaz de auto-gerenciar-se, tomando decisões importantes relacionadas com sua vida pessoal e profissional e consegue analisar problemas e situações conseguindo a solução mais adequada para si, é óbvio que ele não pode nem deve ter a mesma forma de aprender que crianças em formação. Essas alterações que surgem no adulto evidenciam-se, segundo Knowles (apud CAVALCANTI, 1999) principalmente porque as pessoas tornam-se independentes, vão aprendendo através da experiência de vida e da sua realidade, tem motivação intrínseca, e são capazes de auto-avaliação.

Nessa nova organização da realidade social apresentada na introdução deste trabalho busca-se alternativas que estimulem um aprendizado mais dinâmico, lúdico e significativo, impondo novas exigências para o processo educacional, principalmente quando este envolver jovens e adultos.

\section{Processo educacional}

O processo educacional está sendo afetado pelas Tecnologias de Informação e Comunicação (TICs) e dessa forma, alguns professores que têm computadores a sua disposição começaram a utilizá-los no contexto educacional de forma que seu aluno pudesse construir seu conhecimento - enfatizando a participação e experimentação desse sujeito na construção de seu próprio conhecimento, por meio de suas interações, modificando as relações entre professor-aluno e também a sua abordagem pedagógica.

Lucena e Fuks (2000) mostram que a questão chave da implantação de novas tecnologias de suporte à educação é fazer com que o aluno tenha interesse e motivação para buscar as informações desejadas, transformando assim o paradigma tradicional da "educação como fábrica", para a "educação como entretenimento". O aluno não está mais reduzido a olhar, ouvir, copiar e prestar contas. Ele cria, modifica, constrói, 
aumenta e assim torna-se co-autor já que o professor configura o conhecimento em estados potenciais (SILVA, 2000).

$\mathrm{Na}$ abordagem construtivista, o desenvolvimento do ser humano é entendido como um processo que se constrói ativamente, nas relações que o indivíduo estabelece com o ambiente físico e social.

Paralelo a isso, a evolução tecnológica e o crescente interesse pela indústria do entretenimento oferecem caminhos alternativos para "incrementar" os processos de ensino-aprendizagem em todos os níveis.

Uma ferramenta pedagógica que se mostra bastante interessante por possibilitar uma aprendizagem mais dinâmica e lúdica é o jogo. Huizinga (2001) encara o jogo como uma função cultural, definindo-o como

[...] uma atividade ou ocupação voluntária, exercida dentro de certos e determinados limites de tempo e de espaço, seguido de regras livremente consentidas, mas absolutamente obrigatórias, dotando de um fim em si mesmo, acompanhado de um sentimento de tensão e de alegria, com uma consciência de ser diferente da vida cotidiana.

Atividades educacionais para adultos devem ainda se valer dos frutos da maturidade atingida, promovendo o aprendizado através da experimentação e da resolução de problemas, valorizando e desenvolvendo as capacidades de crítica e de análise de situações, estabelecendo paralelos com a experiência previamente adquirida. Tais idéias coincidem com alguns dos princípios estabelecidos por Masetto (1992) e corroboram o conceito de que a Andragogia surge como um complemento à pedagogia, reestruturando os processos de ensino a fim de se adequarem à aprendizagem própria de adultos.

Então no próximo tópico procurar-se-á definir o que são jogos educacionais e porque eles cativam não só crianças, mas também jovens e adultos.

\section{Jogos Educacionais}

Para Bittencourt e Giraffa (2003), o jogo se define como um processo intrinsecamente competitivo, em que co-existem as possibilidades de vitória e derrota. Esse sentido de competição deve ser explorado positivamente, em ambientes de resolução de problemas que podem ser projetados e explorados com uma abordagem construtivista. As regras e objetivos desse jogo não precisam ser expressas ao usuário num primeiro momento, podendo ser oferecidas à medida que ele vai avançando na seqüência do jogo ou até mesmo como prêmio para as tarefas concluídas, ao invés de se utilizar o sistema de simples ganho de pontuação.

O jogo deve ser inserido na prática de sala de aula de forma contextualizada, proporcionando a aprendizagem de forma lúdica, com a intervenção do professor e promovendo a interação entre alunos. Contudo, ainda existe muita discussão, e poucas conclusões, sobre como e quais jogos podem ser entendidos como educacionais. Citados 
por Botelho (2004), Dempsey, Rasmussem e Luccassen definem que os jogos educacionais "se constituem por qualquer atividade de formato instrucional ou de aprendizagem que envolva competição e que seja regulada por regras e restrições". Por isso, toma-se neste trabalho como jogos educacionais todas aquelas aplicações que puderem ser utilizadas para algum objetivo educacional e estiverem pedagogicamente embasadas, mostrando-se como motivadores do processo de aprendizagem.

Dessa forma, os jogos podem ser usados em projetos contextualizados, interdisciplinares e para resolução de problemas, sendo que a utilização desses novos recursos modifica a dinâmica do ensino, as estratégias e o comprometimento de alunos e professores. Com esses novos recursos e ferramentas a educação pode ensejar uma aprendizagem construtiva e significativa, na qual o aluno pode aprender de forma mais dinâmica e motivadora.

Esse artigo tem por objetivo atentar ao fato de que a criação de modelos pré-definidos de jogos é viável e importante para o processo de ensino-aprendizagem, assim com a construção de jogos pelos próprios alunos. Para isso, nem sempre se requer um elevado grau de conhecimentos técnicos em se tratando da construção de jogos simples, mas que podem ter grande caráter pedagógico, conforme se verificou em experiências de utilização de dois softwares de autoria: Hot Potatoes e Macromedia Flash MX. Ambos foram utilizados no desenvolvimento de jogos educacionais interativos e com recursos multimídia por estudantes de Pedagogia e educadores. Essa experiência ocorreu em situações distintas: alunos da graduação do curso de Pedagogia e alunos da PósGraduação em Informática na Educação.

\section{A experiência dos alunos como co-construtores e desenvolvedores de jogos educacionais}

O desenvolvimento de jogos educacionais envolve a escolha de um tema, público alvo e objetivos. Além disso, é preciso ter um esboço de como o material será organizado. Bittencourt e Giraffa (2003) definem que

No planejamento de jogos e simulações é de vital importância definir e fixar os objetivos da atividade, a determinação do contexto desejado para a mesma, a identificação dos recursos utilizáveis para se alcançar os objetivos finais e a determinação da seqüência de interações.

Atualmente, existem no mercado, alguns softwares que possibilitam a criação de jogos educacionais, com destaque para o Hot Potatoes e o Macromedia Flash MX. Ambos não foram desenvolvidos especialmente para a criação de jogos; contudo, devido à combinação de interfaces intuitivas com barras de ferramentas que possibilitam a inserção de imagens, sons, vídeos e botões interativos, é possível a criação de jogos por alunos e professores, possibilitando que os mesmos possam ser criados de acordo com suas necessidades e realidade.

Pesquisadores do Centro Interdisciplinar de Novas Tecnologias na Educação (CINTED) acompanharam duas situações: a primeira em que se utilizou modelos pré-definidos de jogos e a segunda em que os próprios alunos desenvolviam seus jogos educacionais. 
Na primeira delas, os alunos do curso de Pedagogia da Universidade Federal do Rio Grande do Sul (UFRGS) que estavam freqüentando a disciplina 'O Computador na Educação' foram solicitados, a serem co-participantes em um jogo de memória ${ }^{1}$ que foi desenvolvido em Javascript com rótulos ou tags do html, no qual os alunos modificavam as figuras de acordo com um assunto de seu interesse. A partir dos resultados obtidos com essa experiência, estamos construindo outros modelos semiprontos, sendo eles:

Linha de tempo, que está sendo desenvolvida através do software Macromedia Flash MX, na qual elementos externos seriam os eventos e figuras associadas bem como as datas. Tais informações serão carregadas de um arquivo externo, embaralhadas pelo movie clip e apresentadas para o aluno que teria que ordenálas.

Jogo de forca, que será desenvolvido também pelo software Macromedia Flash MX, no qual os alunos ou professores poderão incluir um elenco de palavras as quais serão sorteadas a cada nova jogada.

$\mathrm{Na}$ segunda delas, os alunos que estavam freqüentando as disciplinas 'Internet para Educadores' do curso de Especialização em Informática na Educação - Pós-graduação Lato Sensu à Distância e 'Laboratório de Teleducação' do curso de Pós-graduação em Informática na Educação, Stricto sensu da Universidade Federal do Rio Grande do Sul (UFRGS) foram solicitados a desenvolverem jogos educacionais.

Os alunos de Internet para Educadores desenvolveram jogos de palavras-cruzadas utilizando a ferramenta Hot Potatoes sobre os assuntos relacionados com os assuntos discutidos na disciplina. Já os alunos de Laboratório de Teleducação, desenvolveram objetos de aprendizagem ${ }^{2}$ utilizando a ferramenta Macromedia Flash MX contendo jogos os quais abordaram diversos assuntos, entre eles:

Folclore Brasileiro

Colors, Numbers and Prices

Simulação de estruturas de dados

Reciclagem de Lixo

As Gerações de Educação a Distância

Dessa forma, os jogos educacionais podem ser inseridos na prática pedagógica e envolver a realidade dos alunos, estando devidamente contextualizados a atividades trabalhadas em sala de aula e pedagogicamente embasadas.

Em ambos os casos, essas atividades foram propostas de forma contextualizada, inseridas em projetos maiores, nos quais os alunos estavam teoricamente fundamentados, tendo acesso a material sobre a utilização do software em que estavam trabalhando, sobre desenvolvimento de material educacional e seu uso na educação,

\footnotetext{
${ }_{1}^{1}$ Disponível em: http://penta2.ufrgs.br/edu/edu3375/upload/files/jogos/new_game/memoria2.html

${ }^{2}$ Todos os objetos foram cadastrados no repositório de Objetos de Aprendizagem CESTA, disponível em http://cesta.cinted.ufrgs.br/
} 
bem como tutorial específico que atentava às funcionalidades que poderiam trazer interatividade e recursos multimídia aos seus projetos. Os conteúdos foram expostos gradativamente, sempre seguidos de atividades práticas, que quando finalizadas eram disponibilizadas em portfólio virtual, para serem visualizadas pelos colegas e pelos formadores das disciplinas, tendo ambos possibilidade de deixar comentários para os trabalhos dos demais.

Nessas experiências, os alunos mostraram interesse pelo desenvolvimento de tais materiais, pela possibilidade de escolha do tema, principalmente após trabalharem com o material desenvolvido no software em questão. A possibilidade de virem a desenvolver materiais como os que eram realizados em aula se mostraram como grande motivador dos envolvidos. Após uma resistência inicial, por parte de alguns, à medida que iam realizando as atividades práticas, começaram a entender o funcionamento das ferramentas, aumentando gradativamente $o$ conforto $e$ a segurança durante $o$ desenvolvimento.

De uma forma geral, os alunos conseguiram produzir materiais ricos, com qualidade pedagógica e de conteúdo. Gostaram muito de poder inserir informações e imagens a sua escolha e também de desenvolver materiais de seu interesse que pudessem ser utilizados em seus ambientes profissionais. Apesar da grande maioria não ter experiência com softwares de autoria como os trabalhados, ao longo do processo eles foram se familiarizando obtendo bons resultados.

\subsection{Flash MX}

Este software oferece uma interface que agrega diversas necessidades do desenvolvedor de jogos, como criação de recursos gráficos, entre eles imagens .gif e .jpg, e filmes animados no formato .swf; importação de arquivos externos, tais como vídeo e áudio, criados ou editados em outros programas.

Ele possui flexibilidade e interface altamente intuitiva. A versão MX trouxe uma série de inovações, principalmente na linguagem ActionScript 2.0, que é orientada a objetos, contendo recursos como herança de propriedades, criação de classes e utilização de métodos. Por essas razões, o Flash MX se configura como uma excelente ferramenta de autoria, pois com ele podemos desenvolver desde um simples jogo-da-velha até um jogo mais complexo.

Uma outra vantagem que pode ser destacada diz respeito a ele ser um dos softwares de maior aceitação entre os usuários nos últimos anos, considerando-se que ele foi projetado para ser visualizado em páginas da Web, então, é com certeza a melhor escolha para desenvolvimento de material a ser disponibilizado na rede. A tecnologia Flash faz uso de vetores gráficos e compressão de arquivos de som, o que faz com que o tamanho final fique menor do que comparado àqueles criados em outros programas. No desenvolvimento de um jogo, onde os recursos multimídia são largamente utilizados, essas características já se configuram numa grande vantagem em relação a outros softwares disponíveis.

\subsection{Hot Potatoes}


O Hot Potatoes ${ }^{3}$ é um software que possibilita a elaboração de seis diferentes tipos de exercícios interativos, sendo eles: múltipla escolha, perguntas abertas, ordenar frases, palavras-cruzadas, completar lacunas e associação. Ele não é um programa livre, mas pode ser usado para fins educacionais sem nenhum custo.

É possível a inserção de imagens em ambos exercícios e as questões depois de construídas são geradas no formato html.

\section{Considerações finais}

Com a possibilidade de mudanças no paradigma pedagógico e o surgimento das novas tecnologias, tais como o computador, os alunos e professores podem utilizar os recursos tecnológicos a favor de uma prática pedagógica que leve em conta os desejos e necessidades dos alunos. O importante dessas experiências foi que usando ferramentas que geram também exercícios tradicionais foi possível a inversão dessa lógica, fazendo com que os alunos pensem e sejam criativos. Um exemplo, seria ao invés de completar uma cruzadinha, propor que eles elaborem os conceitos a partir das palavras apresentadas.

Com certeza busca-se que as escolas disponham de uma equipe de educadores que utilizem em sua prática pedagógica as novas tecnologias e os recursos disponibilizados por ela, propiciando que os jogos educacionais e a construção destes também façam parte, pois não basta jogar é preciso também criar, inovar.

Assim é de suma importância que os alunos possam realmente ser co-participantes e desenvolvedores de jogos com forma de usar a tecnologia de forma mais ampla.

O surgimento de softwares de mais fácil utilização, como os de autoria descritos permitem que alunos e professores possam criar materiais e jogos educacionais mais adequados ao seu contexto mudando progressivamente o contexto educativo.

A partir de experiências relatadas nas disciplinas da UFRGS, percebe-se que os alunos apesar de apresentarem uma resistência inicial à utilização das tecnologias e principalmente aos softwares, demonstram ao longo e no final do processo a satisfação de terem participado da construção ou ter produzido seu próprio jogo educacional, mostrando aos colegas e professores com orgulho.

Dessa forma, o nosso grupo de pesquisadores continua as pesquisas em torno de jogos educacionais, referentes a construção de arcabouços semi-prontos e do desenvolvimento destes por alunos e professores, buscando resultados e incentivando que cada vez mais esse tema seja discutido e esteja presente na formação de alunos de todos os níveis de ensino, principalmente no de jovens e adultos, respeitando as especificidades e características dessa categoria.

\footnotetext{
${ }^{3}$ É possível obter mais informações sobre o software através do site http://web.uvic.ca/hrd/halfbaked/ V.3 $\mathrm{N}^{\circ} 2$, Novembro, 2005
} 
Referências

BARBOSA, Laura Monte Serrat. Projeto de trabalho: uma forma de atuação psicopedagógica. 2.ed. Curitiba: L. M. S, 1998.

BITTENCOURT, João Ricardo; Giraffa, Lucia Maria. Modelando Ambientes de Aprendizagem Virtuais utilizando Role-Playing Games. In: SBIE, 2003.

BOTELHO, Luiz. Jogos educacionais aplicados ao e-learning. Disponível em http://www.elearningbrasil.com.br/news/artigos/artigo_48.asp, acessado em janeiro de 2004.

CAVALCANTI, R. A. Andragogia: a aprendizagem nos adultos. Revista de Clínica Cirúrgica da Paraíba. Paraíba: s.edit., nº 6, ano 4, (julho de 1999).

HUIZINGA, Johan. Homo Ludens: o jogo como elemento cultural. São Paulo: Editora Perspectiva, 2001.

LUCENA, C., FUKS, H. A Educação na Era da Internet. Rio de Janeiro: Clube do Futuro, 2000.

MAKAR, Jobe. Macromedia Flash MX Game Design Demystified: The Official Guide to Creating Games with Flash. Berkeley, CA: Peachpit Press, 2002.

MASETTO, M. T. Aulas vivas: tese (e prática) de livre docência. MG Editora. São Paulo, 1992.

SILVA, M. Sala de Aula Interativa. Rio de Janeiro: Quartet, 2000. 